\title{
ADOLFO SÁNCHEZ VÁZQUEZ (1915-2011): REPUblicano, Filósofo y HuMANISTA
}

Adolfo Sánchez Vázquez es una de las grandes figuras intelectuales del mundo iberoamericano.La trascendencia de su vida y obra se puede apreciar de muchas maneras entre las que podríamos destacar tres ámbitos: marxismo crítico, humanismo y filosofía. Estos tres ámbitos están estrechamente vinculados, son interdependientes y tienen un fundamento común, que en términos del propio Adolfo Sánchez Vázquez podemos resumir en la "congruencia de un intelectual comprometido" con la emancipación de los seres humanos para realizar valores e ideales como la libertad, la justicia y la democracia, valores por los que luchó toda su vida, desde su más temprana juventud y por los que fue desterrado.

El destierro marca toda su vida y toda su obra. Como él mismo confiesa, el destierro nunca terminó:

\footnotetext{
Ahora bien, para nosotros, así como para la inmensa mayoría de los exiliados que lo vive, sobre todo en los primeros diez o doce años, como destierro, el exilio no es un simple trasplante de una tierra a otra, un hallar en la nueva lo que se ha perdido al dejar forzosamente la tierra propia, sino la pérdida de la raíz, del centro. Es un vivir en el aire, partido en dos, entre la tierra que se pisa y la tierra con la que se sueña volver, es un estar entre lo hallado y lo perdido, absorbido por un pasado que no pasa y un futuro que no llega. (Sánchez Vázquez 2006, 31)
}

Esta situación existencial de estar suspendido en el aire "entre un pasado que no pasa y un futuro que no llega" constituyó para Sánchez Vázquez un acicate vital para sobreponerse al destino y dotar de sentido su vida y su obra intelectual. Y ese sentido fue precisamente el compromiso con la crítica radical a la injusticia y la opresión social del mundo capitalista, a la dominación ilegítima que ahoga la libertad de las personas y pueblos en todos los estados, tanto los liberales como los socialistas, así como con la tenaz voluntad de realizar por medio de la razón y la esperanza la utopía de un mundo donde todas las personas podamos desarrollar plenamente nuestras capacidades humanas. Este compromiso humanista llena toda la vida y obra de Adolfo Sánchez Vázquez.

En uno de sus últimos libros, Una Trayectoria Intelectual Comprometida, Sánchez Vázquez nos ofrece una reflexión personal y existencial de su quehacer político, poético y filosófico, en relación con las circunstancias históricas y situaciones políticas específicas que motivaron su producción intelectual y sobre las que contribuyó a su transformación, a través de su praxis intelectual. En este texto Adolfo Sánchez Vázquez divide su vida en tres etapas: la República española (1931-1936); la Guerra Civil (1936-1939) y el Exilio en México (desde junio de 1939). Las primeras dos etapas, las más cortas pero las más intensas y dramáticas, corresponden principalmente a su actividad política en defensa de la naciente Segunda República española. Ahí su actividad intelectual se expresa principalmente a través de la Poesía y, como él nos dice, se combina y alterna con la actividad política en las Juventudes Comunistas y después en el propio Ejército republicano. En la tercera etapa, la más duradera, la más productiva y la que más honda huella ha dejado, la actividad política en cuanto tal disminuye continuamente, pero no se extingue, sino que se transforma en un quehacer filosófico riguroso, crítico y comprometido. Veamos las características de estos dos periodos de su vida: el 
político-poético propiamente español y el filosófico crítico, primordialmente mexicano. Ambos periodos constituyen en su devenir e interacción complementaria el quehacer humanístico de Adolfo Sánchez Vázquez.

\section{Lucha republicana y la creación poética.}

Desde su temprana juventud, Sánchez Vázquez unió entrañablemente su formación en la literatura española y latinoamericana con su vocación socialista y republicana que se manifestaba en su militancia en las Juventudes Comunistas. De esta temprana y entrañable vocación resultó su poesía escrita antes, durante y después de la Guerra Civil entre Málaga, Madrid y México. La primera colección de poesías se llama "Poesía en Vela”. Nos dice Sánchez Vázquez:

Para comprender esta "espera”, este estar "en vela”, hay que trazar, aunque sea a grandes rasgos, el contexto político y social de aquellos años, los de la República, que se proponía lo que durante siglos ha sido imposible: modernizar el país, democratizar su vida política e introducir reformas sociales que hagan más justas las condiciones de vida de los trabajadores de la ciudad y del campo. Pero, en esa vía, los gobiernos republicanos pronto se encuentran con una doble oposición: la de las fuerzas políticas y sociales para las cuales los cambios y reformas van demasiado lejos, y la de los sectores más radicales para los cuales esas reformas se quedan demasiado cortas. La perspectiva sombría de una sublevación militar, en aquellos meses, se vuelve cada vez más probable, y, con ella, se crispan y tensan más y más no sólo las relaciones políticas y sociales, sino incluso las personales. Como en las tragedias clásicas, España se encamina inevitablemente al abismo que se avecina, aunque nadie sospecha la profundidad y duración que ha de tener. Y es durante la gestación de esa tragedia colectiva cuando se gesta también esta "Poesía en vela" angustiada y desesperada. (Sánchez Vázquez 2006, 15)

No obstante su juventud, Adolfo Sánchez Vázquez preveía el inevitable desenlace de la guerra civil y la derrota de la República española por el fascismo. En los meses que anteceden al estallido de la Guerra Civil entre 1935 y 1936, Sánchez Vázquez continuó su creación literaria y escribió el libro de poemas El pulso ardiendo, publicado en México en 1942, gracias a que un compañero suyo del exilio que viajaba en el Sinaia había rescatado los poemas y los trajo consigo. "Estos poemas -nos dice Adolfo- fueron escritos en España, ya en vigilante y dramática espera de la tragedia colectiva de mi patria. Al salir a la luz, los dedico al pueblo a quien debo el tesoro que más aprecio: una salida a la angustia y a la desesperanza". ¿Cuál es ese pueblo? La respuesta, creo, es que Sánchez Vázquez se refiere a sus dos pueblos: el español de origen, el mexicano de destino. Ambos constituyen la fuente de su esperanza y el sentido generoso de su vida. Así se empezaba a tejer lo que después reconocerá explícitamente como sus dos raíces.

En plena guerra, entre 1936 y 1938, Adolfo Sánchez Vázquez continúa con su creación poética, al mismo tiempo que participa como militar republicano en el frente de batalla. Él mismo nos dice:

Se trata de una producción breve pues la actividad del poeta se concentra, sobre todo, en hacer la guerra, en contribuir a la lucha del pueblo, primero, en Málaga, como dirigente socialista juvenil, después en el Madrid sitiado, como director del periódico Ahora, órgano central de las Juventudes Socialistas Unificadas y, más tarde en el frente, participando en las batallas de Aragón, Teruel y el Ebro. (Sánchez Vázquez 2005, 26) 
El "Romance de la defensa de Málaga" es uno de los más dramáticos poemas que Sánchez Vázquez escribió unos días antes de la caída de esa ciudad, se trasmitió por radio y se publicó en la prensa local en aquellos terribles días. Este poema termina con un enérgico exhorto:

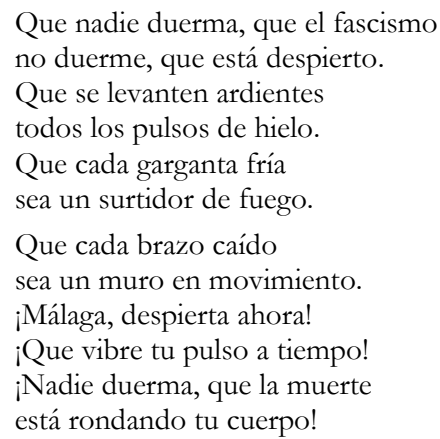

Como bien señala María Dolores Gutiérrez Navas, editora de la poesía de Adolfo Sánchez Vázquez, los poemas escritos al fragor de la guerra civil ayudaron mucho para mantener y elevar el ánimo y la esperanza de los combatientes republicanos.

Ya en el exilio, en situación precaria, Sánchez Vázquez continua su actividad poética y escribe "Sonetos del destierro", con los cuales prácticamente termina su creación poética, a excepción de su par de poemas inéditos, uno de ellos dedicado a León Felipe. Los "Sonetos del destierro" son expresión viva del dolor del "desgarrón" del exilio, que divide su existencia entre España y México.

A partir de que la esperanza del regreso a la patria originaria se extingue, la pasión poética de Adolfo Sánchez Vázquez calla y da paso a su riguroso y creativo pensar filosófico, el cual se desarrolla en su nueva patria y ocupa la mayor parte de su vida. La experiencia trágica de la guerra y del exilio no se olvida, pero su expresión filosófica se vuelve ahora optimista, se proyecta hacia el futuro, hacia la construcción intelectual de una utopía socialista, inspirada en el pensamiento marxista y en la tradición humanista hispanoamericana.

\section{Filosofía y bumanismo hispanoamericano}

A su llegada a México, con la experiencia trágica de la guerra a flor de piel y la angustia del destierro, Sánchez Vázquez encontró en los primeros años de exilio una salida a través de la creación poética. Pero esto sólo fue por pocos años. Pronto se percató de la necesidad de un viraje en su quehacer intelectual y, como sucedió con otros exiliados como Joaquín Xirau y José Gaos, descubrió en México la persistencia de una importante tradición humanista común a todas las naciones hispanoamericanas de los dos hemisferios, tradición que se remonta por lo menos al Renacimiento y que constituye una fuerza espiritual emancipadora, a la cual describe en los siguientes términos: 
Ciertamente la patria que duele o a la que se exalta y se sueña o idealiza no tiene nada que ver con la España imperial, eterna de la doctrina franquista de la hispanidad. Es en verdad su antítesis: la España quijotesca humanista que a lo largo de los siglos desde Luis Vives y Bartolomé de las Casas hasta Antonio Machado ha tratado de liberarse una y otra vez -la guerra civil ha sido su último y frustrado intento- de su carroña espiritual y su miseria material. (Sánchez Vázquez 2003a, 65)

Esta tradición humanista y republicana tiene un arraigo profundo no sólo en España, sino también en México, particularmente en la Universidad Nacional Autónoma de México. Es importante recordar que, desde la fundación de la real Universidad de México en 1553, Alonso de la Veracruz, catedrático de la Facultad de Artes y de Teología, comprometió su quehacer filosófico en la defensa de los pueblos indígenas y criticó las pretensiones de legitimidad de la Guerra de Conquista del imperio español y de la explotación de los indios, de manera muy semejante a como lo habían hecho Francisco de Vitoria y Bartolomé de las Casas. Es el espíritu de esa misma tradición que comparten estos humanistas con los republicanos del exilio, lo que motiva a Adolfo Sánchez Vázquez en su crítica radical a la explotación capitalista y su inquebrantable defensa de la libertad de todos los pueblos, de todas las clases sociales, de todos los hombres que sufren injusticias. En una ocasión, con su aprobación, me permití señalar algunas analogías entre Adolfo Sánchez Vázquez y Alonso de la Veracruz. Ambos filósofos comprometieron su quehacer intelectual con la defensa de los derechos de los pueblos y en contra del poder económico y político; ambos consideraron que la filosofía debe contribuir a la crítica de las injusticias y a la transformación de la realidad opresiva.

Pero cabría preguntarnos si un pensamiento humanista políticamente comprometido, como el que comparten Alonso de la Veracruz y Adolfo Sánchez Vázquez, puede ser considerado como filosofía. Como bien señala José Gaos, la respuesta depende de qué entendamos por filosofía. Si por ella entendemos un sistema teórico de naturaleza metafísica y de aspiración universal, entonces, el humanismo iberoamericano "representa una máxima distanciación del pensamiento relativamente a la filosofía". Si, por el contrario, también se incluye en la filosofía la reflexión crítica para comprender las circunstancias específicas y proponer soluciones a los problemas más importantes que se generan en la cultura, la sociedad, la política del mundo real, reconociendo la esencial diversidad de la reflexión filosófica, su carácter dialógico y falible, entonces, ciertamente nuestro humanismo es "una manifestación de la filosofía hasta de relieve singular" (Gaos 1990, 96).

Veamos brevemente el desarrollo filosófico de Adolfo Sánchez Vázquez en el marco del humanismo republicano iberoamericano. Sánchez Vázquez no combinó simultáneamente en su quehacer humanístico la creación poética y la reflexión filosófica, pero su primera investigación en este campo versó sobre el arte, dando origen a su Tesis de Maestría en Filosofía Conciencia y realidad en la obra de arte (UNAM, 1956). Sánchez Vázquez trabajó durante largo tiempo en la estética filosófica, donde su principal contribución fue el desarrollo de una perspectiva marxista crítica, antidogmática e innovadora, que representaba "[...] un viraje radical al cabo de un proceso de dis- 
tanciamiento, cada vez mayor, del marxismo 'ortodoxo' soviético, provocado por ciertos acontecimientos políticos y de orden teórico” (Sánchez Vázquez 2006, 45).

Dentro de la Estética uno de sus libros más importantes es Las Ideas Estéticas de Marx (1965). La idea central de este libro, ampliamente influyente en todo el mundo iberoamericano tanto en el ámbito filosófico como en al artístico, la resumimos en la siguiente cita:

El arte se presenta, pues, cualesquiera que sean sus formas históricas concretas, como una expresión de la capacidad creadora del hombre, limitada o negada, hasta ahora, en el trabajo. Esta concepción del arte, que desarrollo en mi libro, por su universalidad, es aplicable a todas sus formas históricas y a las diversas formas particulares de hacer arte. Por ello, no puede aceptarse que el arte se identifique o se reduzca a una forma histórica particular en su devenir histórico. (Sánchez Vázquez 2006, 48)

Aunque en los últimos años de su vida, Adolfo Sánchez Vázquez volvió a investigar sobre temas de estética y literatura el trabajo sobre estos temas constituye el preámbulo de su principal y más valiosa contribución: la filosofía de la praxis que constituye una ampliación y generalización de sus investigaciones estéticas.

Sánchez Vázquez desarrolla la idea de praxis como actividad creadora y transformadora de la vida social, principalmente de la ética y la política. Si bien la inspiración de este trabajo surge del pensamiento de Marx, la interpretación crítica y reflexiva que de él hace Sánchez Vázquez le permite producir un pensamiento verdaderamente original y al mismo tiempo contribuir al desarrollo de un marxismo profundamente humanista y libre de todo el dogmatismo y reduccionismo que predominaba en las versiones oficiales hacia mediados del siglo XX.

En su libro Filosofía de la Praxis (1967), al que el propio Sánchez Vázquez considera su obra más importante, concibe a la praxis como una actividad creadora fundada en el conocimiento teórico rigurosamente justificado. Pero, precisamente, la justificación epistémica de la teoría está en función de su efectividad para transformar la realidad circundante, de acuerdo a fines y valores ética y políticamente fundamentados. Si no reconociéramos el carácter práctico, sustantivo, real y material de las teorías científicas y de las humanidades, no podríamos concebir a la filosofía como una práctica transformadora, como lo ha sido en el caso de Adolfo Sánchez Vázquez:

La premisa fundamental de la verdadera filosofía de la praxis es verse a sí misma no sólo como una reflexión sobre la praxis, sino como un momento de ella y, por tanto, con la conciencia de que siendo teoría sólo existe por y para la praxis. (Sánchez Vázquez 2003b, 326

La filosofía como praxis es pues una actividad orientada por valores éticos, políticos, estéticos y epistémicos, cuya concreción exige la transformación de la realidad, la realización de la utopía. En este sentido la praxis filosófica es una compleja virtud, a la par teórica y práctica, que integra una pluralidad de valores. Por ello Sánchez Vázquez enfatiza la actividad de filosofar sobre la obra filosófica misma. Filosofar para él "significa cierta relación con un mundo que no nos satisface y, con ella, la aspiración, el ideal o la utopía de la transformación” (Sánchez Vázquez, 2003a, 63).

Desde el punto de vista de la filosofía de la praxis, la filosofía, las ciencias, las humanidades y las artes integran de diferentes modos el conocimiento objetivo con el ideal utópico, la justificación epistémica o estética y el compromiso ideológico, ética y políticamente responsable. 


\section{Congruencia de un bumanista}

La praxis filosófica y en general humanística de Adolfo Sánchez Vázquez es una de las expresiones recientes más valiosas de esta tradición centenaria que México comparte con España, y con todo el mundo iberoamericano. Este humanismo republicano rebelde y emancipador constituye la más importante contribución del mundo iberoamericano al pensamiento universal y sin lugar a dudas Adolfo Sánchez Vázquez es uno de sus más conspicuos representantes.

Adolfo Sánchez Vázquez fue un filósofo original y riguroso, un admirado y querido profesor, un ejemplo de honestidad y compromiso intelectual, moral y político, un crítico radical de la injusticia, la explotación y el autoritarismo, un constructor de utopías, en suma un humanista republicano, congruente durante toda su vida. Y es esta gran virtud la que le permitió trasmutar el desgarrón del exilio en pensamiento creativo y optimista que enriquece la tradición humanista iberoamericana, tanto en España como en América. Por eso para Adolfo Sánchez Vázquez "lo decisivo no es estar -acá o allá- sino cómo se está":

Al cabo del largo periplo del exilio, escindido más que nunca, el exiliado se ve condenado a serlo para siempre. Pero la contabilidad dramática que se ve obligado a llevar no tiene que operar forzosamente sólo con unos números: podrá llevarla como suma de pérdidas, de desilusiones y desesperanzas, pero también, -¿por qué no?- como suma de dos raíces, de dos tierras, de dos esperanzas. Lo decisivo es ser fiel -aquí o allí- a aquello por lo que un día se fue arrojado al exilio. Lo decisivo no es estar -acá o allá- sino cómo se está. (Sánchez Vázquez 2003c, 572)

Ambrosio Velasco Gómez

UNAM

ambrosio@unam.mx

\section{REFERENCLAS}

Gaos, José. 1990. Pensamiento en Lengua española. En Obras Completas, Tomo VT: Pensamiento en lengua española. Pensamiento español. México: Universidad Nacional Autónoma de México.

Sánchez Vázquez, Adolfo. 2003a. El imperativo de mi filosofar. En A tiempo y destiempo, 55-63. México: Fondo de Cultura Económica.

Sánchez Vázquez, Adolfo. 2003b. Una nueva práctica de la filosofía. En A tiempo y destiempo, 320-330. México: Fondo de Cultura Económica.

Sánchez Vázquez Adolfo. 2003c. Fin del exilio o exilio sin fin. En A tiempo y destiempo, 569-572. México: Fondo de Cultura Económica.

Sánchez Vázquez, Adolfo. 2004. De la estética de la recepción a la estética de la participación. México: Facultad de Filosofía y Letras (Universidad Nacional Autónoma de México), Colección Relecciones.

Sánchez Vázquez, Adolfo. 2005, Poesía, México, Fondo de Cultura Económica.

Sánchez Vázquez, Adolfo. 2006. Una trayectoria intelectual comprometida. México: Facultad de Filosofía y Letras (Universidad Nacional Autónoma de México), Colección Relecciones.

Sánchez Vázquez, Adolfo. 2009. Incursiones literarias. México: Universidad Nacional Autónoma de México. 